\title{
Annual variations in the severity of attack by Argentine stem weevil on perennial ryegrass
}

\section{W.F. HUNT}

DSIR, Grasslands, Private Bag, Palmerston N orth

\begin{abstract}
Experiments on the effects of Argentine stem weevil (Listronotus bonariensis (Kuschel)) predation on perennial ryegrass (Lolium perenne L.) were carried out at Palmerston North from 1978 to 1986. A tagged tiller technique was used to assess the probability that any tiller would be attacked by Argentine stem weevil larvae. After grazing by sheep, a single tiller was tagged with a plastic ring at 25 sites $15 \mathrm{~cm}$ apart along line transects through each plot, and examined twice weekly throughout the seasons during which Argentine stem weevil is active. Annual variation at Palmerston North was substantial, with the probability of a low endophyte 'Grasslands Nui' perennial ryegrass tiller being attacked ranging from $55 \%$ to $95 \%$. ASW annual larvae production calculated from the probability of tiller site damage and the tiller site density varied from 800 to $3000 / \mathrm{m}^{2}$. Variations in the severity of attack of this magnitude are sufficient to -explain the--variability in -the success of sowings of low endophyte grasss. Variations in annual larvae production were not correlated with weather parameters, but may be related to natural cyclic disease infestations.
\end{abstract}

Keywords Argentine stem weevil, 'Grasslands Nui' perennial ryegrass, endophyte

\section{Introduction}

The Argentine stem weevil Listronotus bonariensis (Kuschel) is a serious pasture pest, particularly of drought-prone regions of the southern North Island and central South Island of New Zealand. The effects of the pest are less obvious in Southland, and anecdotal evidence suggests they vary in intensity in other districts from year to year.

The severity of Argentine stem weevil (ASW) damage has been shown to be influenced by genotype, endophyte infection, and nitrogen nutrition (Prestidge et al. 1982; Gaynor \& Hunt 1982,
1983), but no data have been produced to indicate the extent of annual variations in severity. Large annual variations may suggest some environmental or cyclic influences on ASW population trends that could be exploited. Large annual variations could also mean that conclusions made on a single year's data could be highly misleading.

Barker \& Addison (1989) contend that progress in the development of control strategies for ASW has been handicapped by the lack of numerical sampling plans and extraction techniques for monitoring population levels. They review a number of previous techniques for determining ASW populations and life cycle stages at any one point of time, but none of these techniques measure the total ASW production on an annual basis. The technique described here and by Hunt \& Gaynor (1982) and Hunt et al. (1988) has features which enable stem weevil activity to be compared on an annual basis.

Interactions between ASW, endophyte, nutrition and ryegrass genotype (Hunt \& Gaynor 1983) have been studied at DSIR Grasslands for 7 summers between 1978-79 and 1985-86. In this paper, these data are used to estimate annual variations in ASW larval production, taking advantage of the fact that all experiments contained newly sown monoculture swards with the same genotype, endophyte content and nutrition level, and were sown at the same location.

\section{Methods}

The data were gathered from four experiments sown in November 1976, May 1979, April 1981, and March 1984 at DSIR Grasslands, Palmerston North, on a Karapoti brown sandy loam. Each experiment included a treatment of 'Grasslands Nui' perennial ryegrass (Lolium perenne L.) sown in monoculture (within 1 or 2 years of measurement) with low nitrogen nutrition $(50 \mathrm{~kg} / \mathrm{ha} \mathrm{N}$ per year). Other mineral elements were non-limiting to growth.

The level of endophyte in Nui was not tested individually for each experiment before 1982, but the same seed source (DSIR Grasslands breeders' seed) was used for all experiments. The endophyte level of pre-basic (breeders') seed was found to be relatively low (10 to $48 \%$ with a mean of $28.5 \%$ ) in 1982 by Scott (1983). Recent tests of reserved samples kept in 
ideal conditions of these lines showed endophyte infection to be relatively low $(35 \%)$ for the November 1976 sowing, but much higher (77\%) for the April 1981 sowing (G.C.M. Latch per, comm.). However, ASW damage was very high in the 1981-82 summer, indicating that most of this endophyte must have been lost from the batch of seed actually used for the April 1981 trial. The importance of cool dry storage conditions for endophyte survival (Rolston et al. 1986) was not appreciated at this time.

After 1982, "low-endophyte" (0 to $10 \%$ endophyte infection) was sown in all experiments.

A non-destructive method was used to monitor stem weevil larval activity. A random sample of 25 tillers per rep. was tagged with plastic rings and inspected twice weekly for a certain measurement period during the season. There were 4 reps in most years, except for 1981-82 and 1982-83 when there were 3 reps. Each tagged tiller established a tiller "site", spaced sufficiently from its adjacent sites (15 $\mathrm{cm}$ was considered sufficient) to preclude the possibility of a single larva damaging more than one site. Emerging tillers were included in the tiller sites, and hence tillering did not change the site density. Larval damage at the site was identified from the characteristic damage to the youngest growing leaf, the presence of frass, or the presence of larval exit holes in the pseudostem. Further examination of the above evidence would sometimes reveal live larvae. If the tagged tiller died before stem weevil damage appeared, another undamaged tiller was tagged to replace it.

Because tiller sites were examined for stem weevil larval damage, the number of tillers occupying that site is irrelevant. This precludes the problem of variable rates of tillering between years, and changes in tiller density with time.

Fresh tiller sites were established during the stem weevil season whenever a high proportion of the current sites had been damaged. This was necessary because the rate of damage may be inaccurate if calculated from too few undamaged sites.

Tiller densities were determined at intervals from randomly placed $2.25 \mathrm{~cm}^{2}$ quadrats harvested to ground level with scalpels, cutting individual tillers once only.

The data are used in two ways to illustrate the stem weevil larval infestation. First, the probability of a site being damaged by stem weevil during the season (P) can be estimated. If the proportion of sites damaged in successive tiller site taggings is p, pl, p2, p3 ... respectively, then

$$
\begin{gathered}
P=p+p 1(1-p)+p 2(1-p)(1-p l) \\
+p 3(1-P)(1-P 1)(1-p 2)
\end{gathered}
$$

Secondly, the peaks and troughs of larval damage can be identified from the percentage site damage rate $(\mathrm{R})$, calculated as

$$
\mathrm{R}=\frac{\text { sites damaged during }(\mathrm{t} 2-\mathrm{t} 1) * 100}{(\mathrm{t} 2-\mathrm{tl}) * \text { number of undamaged sites }}
$$

Site damage rates can be used to compare treatment effects on ASW damage within a year, but year to year comparisons need to take into account variations in tiller density between years. This is done by estimating total larvae produced per $\mathbf{m}^{2}$ per year from the site damage data and the site density data. The site density is the tiller density at the time of tiller site tagging.

As $\mathrm{p}, \mathrm{p} 1, \mathrm{p} 2, \mathrm{p} 3$. . . is the probability of a site being damaged by a larva for successive tiller site taggings, and there is only one larvae per tiller (Barker et al. 1981), and sites are too far apart for one larva to damage more than one site (see above), p, Pl. p2, P3 ... also measure the probability of at least one larva being present at that site during that period. All larvae were detected when they reached a size when they were able to cause visible damage, so larval size and instar stage were unimportant.

A site with more than one tiller may harbour more than one larvae, and to that extent the data would underestimate larvae production. However, this source of error is not considered significant, as most sites contained only one tiller for most of the trial, and the time required for extra tillers to grow from the original tagged tiller in a site large enough for an adult to lay eggs, and the hatching larvae to develop large enough to cause visible damage would be lengthy relative to the interval between taggings of 2-3 months

For each site tagging (measurement) period, the stem weevil larvae production is calculated as the product of the site density at the beginning of the period, and the probability of larva appearance at a site during that period, divided by the number of tiller sites a single larvae may damage (taken as 3 ). There are few estimates in the literature of the number of tillers a larva may damage. Barker et al. (1981) stated that each larva may destroy one, 2 or more tillers during its development, and 3 tillers appears to be a commonly accepted estimate (A. Popay, D. Gaynor pers. comm.). It was observed in the trials reported on here, that where tagged tillers had produced a number of small daughter tillers, and that tagged site harboured a larva, often all the small tillers were damaged, in some cases more than 3 .

The stem weevil larvae apparent during the season is the sum of the stem weevil apparent during periods within that season.

The precision of the individual estimates (D) was calculated as the ratio of the standard error of the mean to the mean (Barker \& Addison 1989).

\section{Results}

Site damage

ASW damage was evident at the Palmerston North location in every year tested, but the rate at which tillers in tagged sites were damaged varied considerably from year to year (Figure 1). The probability of a tagged tiller site being damaged 


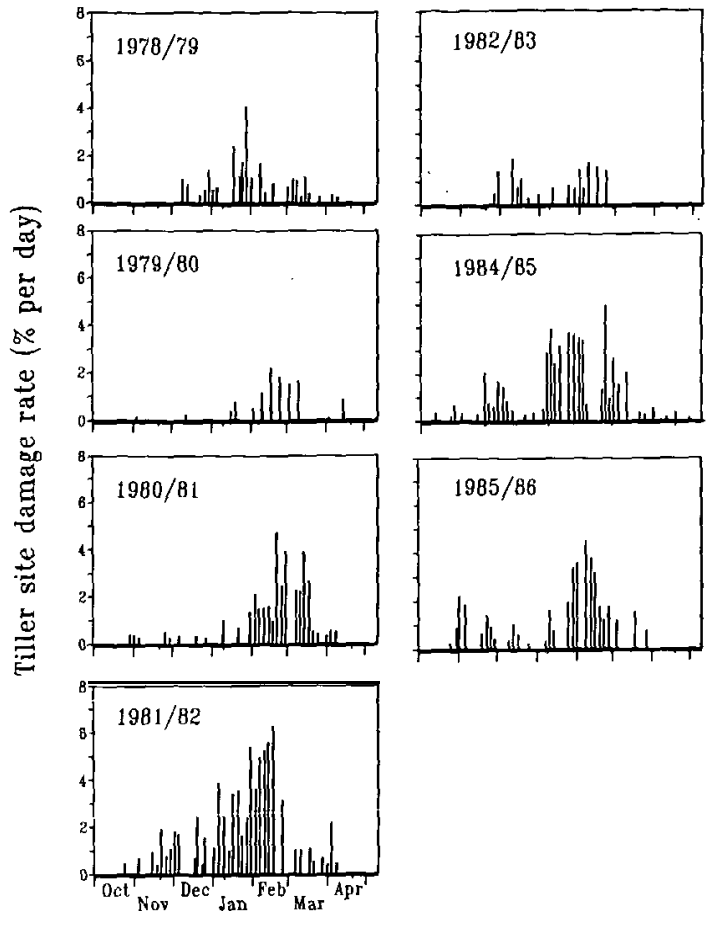

Month for each year

Figure 1 Tagged tiller site damage by Argentine stem weevil larvae attacking 'Grasslands Nui' (low endophyte) ryegrass sown in monoculture with low nitrogen nutrition for each year of experiment.

varied-from 0.55 in-1982-83-to-0:95-in-1981=82. The peak in site damage rate also varied from January 1978-79 to late February 1984-85. Two peaks in site damage could be detected in 1981-82, 1982-83, 1984-85, and 1985-86.

The mean tiller density and hence the site density (the tiller density at time of tagging) varied considerably from 3775 (1982-83) to 8218 (1980-81) tillers per $\mathrm{m}^{2}$ (Fig. 2). No tiller density measurements were made in 1985-86.

\section{Larvae production}

Estimates of the ASW larvae -produced each year, calculated from the tiller site density, the probability of site damage data, and assuming larvae on average visibly damage 3 tillers each, showed considerable annual variation from a low of $816(1982-83)$ to a high of 3000 (1980-81) larvae per $\mathbf{m}^{\mathbf{2}}$ per year (Figure $3)$. As no site data densities were available for 1985-86, the calculation represents the larvae that would have been produced if the site densities were the same as the previous year. This was done because the data for both years were collected on the same swards.
The precision of the individual site damage estimates (D) varied from 0.018 to 0.177 with a mean of 0.055 . The precision of the larval density estimates (D) varied from 0.03 to 0.39 , with a mean of 0.148 .

\section{Discussion}

The Palmerston North site is suitable for ASW studies as damage was consistently detected in every year of the experiment, and in some years the probability of damage approached 100\% (Figure 3). The precision of the estimates of site damage and annual larval production were well within the limits considered acceptable for field studies on insect populations (Barker \& Addison 1989).

The comparison of 7 years' data at Palmerston North provides a unique demonstration of large annual differences in both the stage in the season when ASW damage occurs, and the severity of damage between years.

Most years showed a high level of attack around January-February preceded by a smaller peak in November-December. Exceptions were 1982-83 when damage was lowest and the January-February peak was no larger than the November-December peak, suggesting essentially a failure of the second generation. The lack of a November-December peak in 1979-80 and 1980-81 might suggest poor survival of adults after winter in those years.

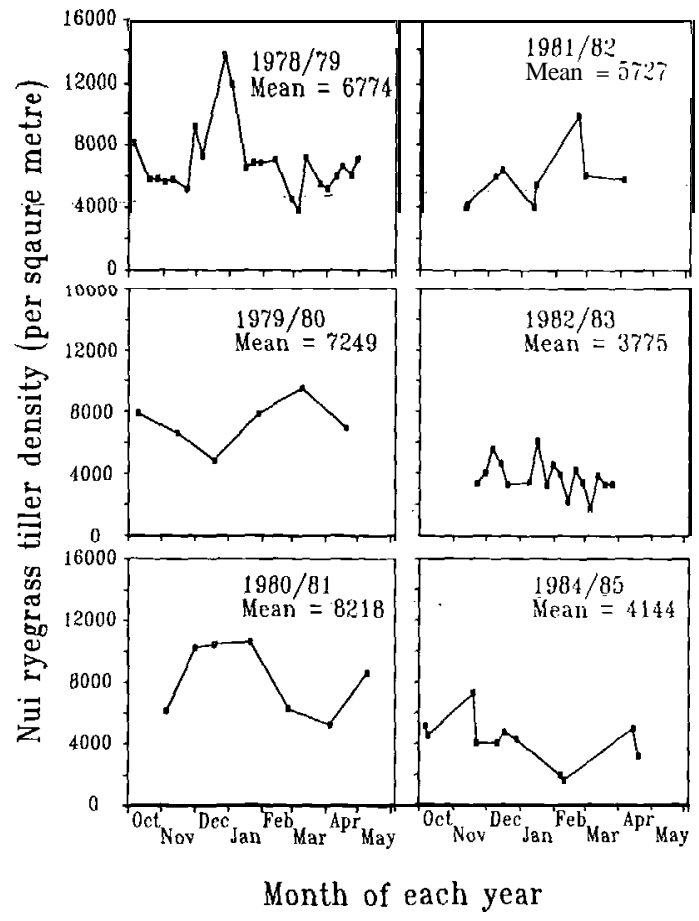

Figure 2 'Grasslands Nui' (low endophyte) ryegrass tiller densities for each year of experiment. 

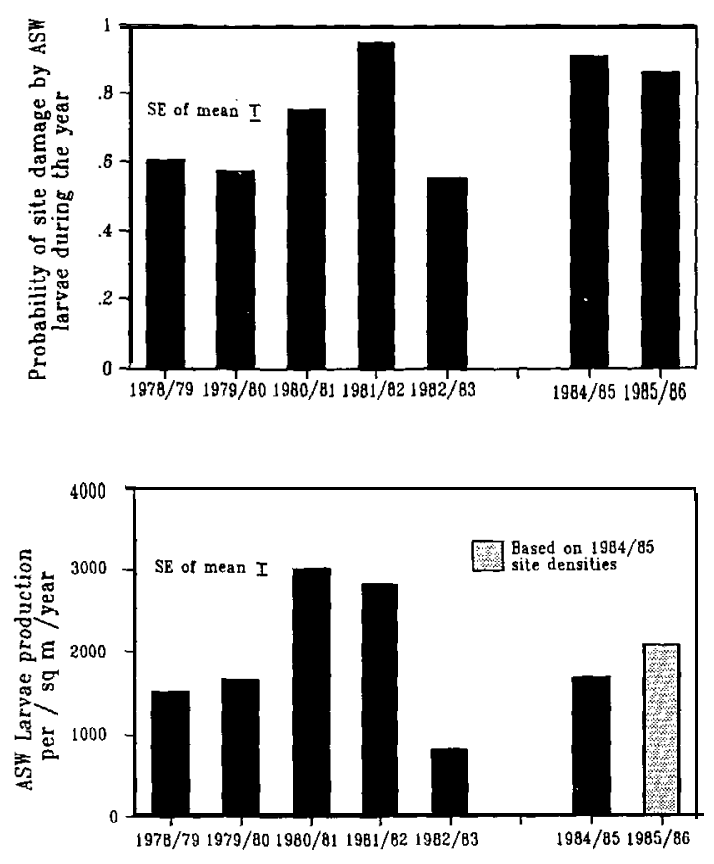

Year of experiment

Figure 3 Probability of Argentine stem weevil larval damage, and estimates of larval production in 'Grasslands Nui' (low endophyte) ryegrass swards for each year of experiment.

The calculated levels of annual larvae production are difficult to assess in view of the lack of previously published estimates. Even though the larval stage is that which causes the devastating damage to ryegrass, no previous attempts to assess annual ASW production, larval or adult, could be found. The lack of attention to annual production reflects a perception that such data do not relate to the severity of attack at any one point in time. ASW population data in the literature are expressed either as adult densities, or larvae per 100 tillers at a particular point in time, and thus can be expected to be less than larvae production for the whole season.

The larvae production data can be compared with adult density data if allowance is made that the larvae production might make up 2 or 3 generations of adults (Pottinger 1961). Halving the range to 400 to 1500 brings the estimates of larval densities for a generation in line with previously published data. Pottinger (1961) recorded adult weevil populations as high as 1249 per $\mathrm{m}^{2}$ using a slow flooding technique, and hand sorted over 1600 pupae per $\mathrm{m}^{2}$. Other published estimates are lower. Kelsey (1958) considered 215 adults per $\mathrm{m}^{2}$ a heavy infestation, and measured up to 381 per $\mathbf{m}^{2}$ using flooding techniques. May (1960) found up to $200 \mathrm{~m}^{2}$, but Neilson (1964, 1966), also using flooding techniques, recorded only 129-376 adult weevils per $\mathrm{m}^{2}$. Prestidge et al. (1989) found adult populations in February-March 1985 varied from 19 to 279 per $\mathrm{m}^{2}$, and from 87 to 203 per $m^{2}$ in 1986.

The annual larvae production estimates are hence not high, approximating the upper limit of published adult density data. Larvae production in these experiments could be expected to be high, however, considering the low endophyte and monoculture status of the sward (Figure 2). Barker et al. (1986, 1989) consider the density of low endophyte ryegrass tillers to be of major importance in determining ASW population levels. Larval production data might be expected to be higher than adult density data considering that some mortality is likely between the larval, pupal and adult stages (Barker \& Addison 1989).

The main feature of the data in Figure 3 is the large annual variation in the larval production, with the peak year of 1980-81 having over 3 times the larval production of the trough year. Variations of such magnitude could be expected to cause variation in the severity of ASW attack from moderate to devastating, sufficient to explain variations in the persistence of low endophyte ryegrass pastures. Barker et al. (1989) suggest a threshold 200 per $\mathrm{m}^{2}$ third-stage larvae for damage to occur in spring, but 125 per $\mathbf{m}^{2}$ third-stage larvae cause significant damage in summer.

Barker et al. (1989) contend adult stem weevil populations are regulated by the available food resource, i.e. endophyte-free ryegrass tillers. No such relationship could be detected on an annual basis between mean summer tiller density and total larvae production in the data presented here $(\mathrm{r}=0.52)$, and so tiller density does not explain the observed differences in annual larvae production.

The variations in ASW larvae production suggest scope exists for reducing the epidemic levels of ASW larval production if the reasons for the differences could be understood. These may be climatic, but no significant correlations were detected between ASW larval production and climatic parameters tested such as heat accumulation in spring, number of wet days or temperature. The variations may also reflect natural disease control measures that typically produce the cyclic fluctuations in populations suggested in Figure 3, where two years with particularly high larvae production were followed by a year with very low larvae production, and the low year failed to produce the expected large generation in January-February (Figure 1).

\section{Conclusions}

Argentine stem weevil is a significant pest of ryegrass every year at Palmerston North. The annual production of the damaging stage of the ASW, the larvae, may show 3-fold variations from year to year. Annual variations also occur in the relative severity of damage thoughout the ASW season. 
The cause for the annual variations in ASW attack could not be identified, and were not related to ryegrass tiller density or climatic parameters. The cyclic nature of the population trends suggests variations reflect a natural disease control mechanism, and that scope exists to control excessive larval production if such a control mechanism can be identified.

\section{ACKNOWLEDGEMENTS}

D .L. Gaynor and J . J . Dymock (DSIR Plant Protection) cooperated on many of the trials for which D. Calder and V.A. Hunt provided technical assistance. A. Popay (DSIR Plant Protection) provided helpful criticism of the manuscript. V.G. Thomas and R.J. Fletcher (DSIR Physical Sciences) provided statistical advice.

\section{REFERENCES}

Barker, G.M.; Addison, P.J. 1989. Sampling Argentine stem weevil, Listronotus bonariensis (Kuschel), populations in pasture: the soil dwelling stages. NZ journal of Agricultural Research 32: 95-103.

Barker, G.M.; Pottinger, R.P.; Addison, P.G. 1989. Population dynamics of the Argentine stem weevil Listronotus bonariensis in pastures of Waikato, New Zealand. Agriculture, Ecosystems and Environment 26: 79-155.

Barker, G.M., Pottinger, R.P., Addison, P.G. 1981. Argentine stem weevil in Northern North Island Pastures. Proceedings of the Ruakura Farmers Conference 33: 85-89.

Gaynò, D.L.; Hunt, W.F. 1982. Nitrogen and water effects on Hyperodes bonariensis susceptibility in perennial ryegrass in New Zealand (Coleoptera: curculionidae). Proceedings of the 3rd Australasian Conference on Grassland Invertebrate Ecology, Adelaide, K.E. Lee Ed. South Australia Government Printer: 255-263.

Gaynor, D.L.; Hunt, W.F. 1983. The relationship between nitrogen supply, endophytic fungus, and Argentine stem weevil resistance in ryegrass. Proceedings of the NZ G rassland Association 44: 257-263.
Hunt, W.F.; Gaynor, D.L. 1982. Argentine stem weevil effects on Nui and Ruanui ryegrasses grown with two levels of nitrogen/water nutrition. NZ journal of Agricultural Research 25: 593-599.

Hunt, W.F.; Dymock, J. J.; Gaynor, D.L. 1988. Spring and autumn nitrogen effects on susceptibility to Argentine stem weevil in low endophyte Nui ryegrass. NZ journal of Agricultural Research 31: 389-393.

Kelsey, J.M. 1958. Damage in ryegrass by Hyperodes griseus Hust. NZ journal of agricultural research I: 790-795.

May, B.M. 1960. The Argentine stem weevil Hyperodes bonariensis Kuschel on pasture in Auckland. NZ journal of Agricultural Research 4: 289-297.

Neilson, R.L. 1964. Biology and control of stem weevil. Proceedings of the NZ Pest Control Conference 17: $152-156$.

Neilson, R.L. 1968. Biology and control of stem weevil. Proceedings of the NZ Pest Control Conference 19: 177-179.

Pottinger, R.P. 1961. A study on the biology and economic importance of the Argentine stem weevil, Hyperodes bonariensis Kuschel, in New Zealand. M. Agr. Sc. Thesis, Lincoln College Library, $317 \mathrm{p}$.

Prestidge, R.A.; Pottinger, R.P.; Barker, G.M. 1982. An association of Lolium endophyte with ryegrass resistance to Argentine stem weevil. Procedings of the NZ Pest Control Conference 35: 119-122.

Prestidge, R.A.; Van der Zijpp, S.; Gaunt, P. 1989. Effect of Argentine stem weevil on vigour of 'Grasslands Roa' tall fescue under dairying in the Waikato. NZ journal of Agricultural Research 32: 291-297.

Rolston, M.P.; Hare, M.D.; Moore, K.K.; Christensen, M.J. 1986. Viability of Lolium endophyte fungus in seed stored at different contents and temperatures. $N Z$ journal of Experimental Agriculture 14: 297-300.

Scott, D.J. 1983. Lolium endophyte levels in commercial perennial ryegrass seed lines. Proceedings of the $N Z$ Grassland Association 44: 254-256. 